\title{
HMGB1 as an Innate Alarmin Promotes Autoimmune Progress: An Essential Role in the Pathogenesis of Type 1 Diabetes
}

\section{Jixin Zhong ${ }^{1,2 *}$}

${ }^{1}$ Department of Medicine, Affiliated Hospital of Guangdong Medical College, 57 Ren-Ming Road, Zhanjiang 524001, China ${ }^{2}$ Davis Heart and Lung Research Institute, The Ohio State University, 460 W 12th Ave, BRT 350, Columbus, OH 43210, USA

\section{Keywords: HMGB1; Type 1 diabetes; Autoimmune response; $\beta$ cell}

High-Mobility Group Box 1 Protein (HMGB1) is a chromatin associated nuclear protein which was previously thought to function only as a nuclear factor that enhances transcription [1,2]. Recent findings indicate that HMGB1 also acts as an endogenous "danger signal" (alarmin) to alert the innate immune system for the initiation of host defense or tissue repair [3]. HMGB1 was demonstrated to be either passively release or actively secreted and functioned as an inflammatory cytokine. When released from damaged cells or activated immune cells, it activates a variety of immune cells including dendritic cells (DCs), macrophages, neutrophils, and T cells. It has been suggested that HMGB1 is involved in the pathogenesis of multiple autoimmune diseases including Systemic Lupus Erythematosus (SLE), Rheumatoid Arthritis (RA), and Experimental Allergic Encephalomyelitis (EAE) $[4,5]$. We recently demonstrated that HMGB1 is also implicated in the development of type 1 diabetes via activating innate immune response $[5,6]$.

HMGB1 belongs to a family of non-histone chromatin associated nuclear proteins, High Mobility Group (HMG) nuclear protein family. It was discovered as a specific regulator of gene expression in 1973 [7]. HMGB1 is an evolutionarily conserved chromosomal protein, sharing $100 \%$ amino acid (AA) identity between mice and rats, and 99\% AA identity between rodents and humans. As a nuclear factor, HMGB1 exerts diverse cellular functions such as regulating nucleosomal structure and controlling DNA transcription [1,2,8-11]. HMGB1 has two 80-amino acid DNA binding domains (A-box and B-box) and a C-terminal acidic tail (Figure 1). The two boxes are responsible for the DNA binding and stabilization of nucleosomal structure, while the C-terminal acidic tail is important for the transcription stimulatory activity of HMGB1 [5,12-15]. Wang and coworkers re-discovered HMGB1 as a late mediator of lethal septic shock [3]. HMGB1 was found to be increased in the circulation of septic mice and patients. The administration of HMGB1 was lethal in mice. Challenge of endotoxin, Tumor Necrosis Factor (TNF), and Interleukin-1 (IL-1) induced the release of HMGB1 from macrophages. Blockade of HMGB1 by neutralizing antibodies protected mice from endotoxin-induced septic shock [3]. Further studies demonstrated that HMGB1 released from damaged tissue or cell serves as a "danger signal" to alert the innate immune system for exogenous pathogen invasion, endogenous tissue injury, or the presence of inflammatory mediators. Immune system

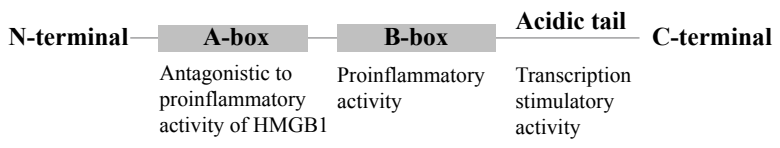

Figure 1: Molecular Characterization of HMGB1

HMGB1 contains 2 homogenous domains - A-box and B-box and an acidic C-terminal tail. B-box is associated with proinflammatory activity and RAGE binding while A-box is a specific antagonist of HMGB1 which inhibits the proinflammatory properties of HMGB1. The $\mathrm{C}$-terminal acidic tail is required for transcription stimulatory function of HMGB1. then initiates host defense or tissue repair processes.

Right after re-discover as an innate alarmin, HMGB1 was suggested to be involved in a variety of autoimmune diseases such as Systemic Lupus Erythematosus (SLE) [16], Rheumatoid Arthritis (RA) [17,18], and Experimental Allergic Encephalomyelitis (EAE) [19]. Using a spontaneous type 1 diabetes animal model (Non-Obese Diabetic mouse, NOD mouse), we demonstrated an essential role of HMGB1 in the development of type 1 diabetes $[5,6]$. Defects in apoptotic $\beta$ cell clearance have been considered as an important cause of type 1 diabetes [20-24], although the underlying mechanisms remain elusive. To illustrate the importance of HMGB1 in this process, we confirmed that HMGB1 could be passive released by apoptotic $\beta$ cells, not only by necrotic cells [6]. Defective clearance of apoptotic $\beta$ cells may thereby results in the accumulation of extracellular HMGB1. The release of HMGB1 subsequently induces DC maturation which can further initiate an immune response against $\beta$ cell antigen in susceptible individuals. In addition to the passive release from damaged $\beta$ cells, HMGB1 is also released from autoreative immune cells by active secretion. Using a neutralizing antibody, we demonstrated that blockade of HMGB1 decreased the incidence of spontaneous T1D, delayed its onset, and reduced the severity of insulitis. To further illustrate the underlying mechanism, we detected $\mathrm{DC}$ and $\mathrm{T}$ cell subpopulations and found HMGB1 neutralization reduced CD11c++ CD11b+ DCs in Pancreatic LyphoNode (PLN), a subpopulation involved in islet antigen presentation. HMGB1 blockade also increased CD4+ Foxp3+ regulatory T cells in PLN and CD11c+CD8+ DCs, a tolerogenic subset of DCs, in spleen. Interestingly, CD8+ IFN $\gamma+$ cytotoxic T cells were increased in the PLN and spleen of mice treated with HMGB1 neutralizing antibody, suggesting a retarded migration of activated autoreactive $T$ cells into the pancreatic islets [6]. Consistent with our findings, blockade of RAGE, a receptor for HMGB1, can also delay the recurrent diabetes in syngeneic islet transplantation and prevent transfer diabetes [25].

Inflammatory response begins with recognition of life-threatening events called "danger signals". According to their origin, those "danger signals" can be categorized into two classes: Pathogen-Associated Molecular Pattern (PAMP) and Damage-Associated Molecular Pattern (DAMP). PAMPs are exogenous molecules derived from life-

*Corresponding author: Jixin Zhong, Davis Heart and Lung Research Institute The Ohio State University, 460W 12th Ave, BRT 350, Columbus, OH 43210, USA Tel: 1-614-556-9777; E-mail: zhongjixin620@163.com

Received November 23, 2012; Accepted November 24, 2012; Published November 27, 2012

Citation: Zhong J (2013) HMGB1 as an Innate Alarmin Promotes Autoimmune Progress: An Essential Role in the Pathogenesis of Type 1 Diabetes. J Biomol Res Ther 2: e108. doi:10.4172/2167-7956.1000e108

Copyright: (c) 2013 Zhong J. This is an open-access article distributed under the terms of the Creative Commons Attribution License, which permits unrestricted use, distribution, and reproduction in any medium, provided the original author and source are credited. 
Citation: Zhong J (2013) HMGB1 as an Innate Alarmin Promotes Autoimmune Progress: An Essential Role in the Pathogenesis of Type 1 Diabetes. J Biomol Res Ther 2: e108. doi:10.4172/2167-7956.1000e108

Pancreatic $\beta$ cell

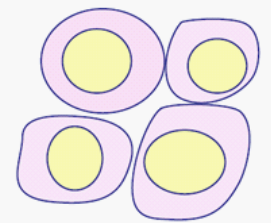

Autoimmune response against $\beta$ cell

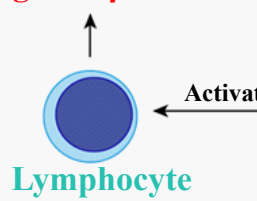

Lymphocyte
Apoptosis
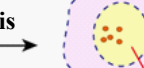

$\therefore$ HMGB1

gure 2: Implication of HMGB1 in autoimmune response against $\beta$ cell. Apoptotic $\beta$ cells release HMGB1, which subsequently activates immune cells such as DCs and macrophages. Activated DCs and macrophages in turn secrete HMGB1 to amplify the immune response. The amplified immune reaction against apoptotic $\beta$ cell then results in an autoimmune response against $\beta$-cell-derived self antigens in genetically susceptible individuals.

threatening pathogens such as lipopolysacharide (LPS) and viral RNA, while DAMPs (also called as alarmins) are endogenous molecules released from damaged cells or tissues such as Heat Shock Proteins (HSPs). HMGB1 is now considered as a novel DAMP, alerting immune system for a tissue damage caused by either sterile inflammation or exogenous pathogen invasion. HMGB1 could be recognized by many receptors including Receptor for Advanced Glycation End products (RAGE) and some members of the Toll-like family of receptors $[5,26]$.

Based on its importance in orchestrating immune responses, HMGB1 has been proposed to be involved in a variety of diseases. In case of autoimmune diabetes, a defective clearance of apoptotic $\beta$ cells results in the release of HMGB1, which subsequently activates immune cells such as DCs and macrophages. Activated DCs and macrophages in turn actively secrete HMGB1 to amplify the immune response, intending to clear damaged $\beta$ cells. In genetically susceptible individuals, however, this process may induce an autoimmune reaction against self antigens derived from $\beta$ cells (Figure 2). The challenge for future studies is to develop a high potent HMGB1 blockade therapy to prevent the progress of autoimmune response against $\beta$ cells and reverse Type 1 Diabetes.

\section{Acknowledgements}

This work is supported by the National Natural Science Foundation of China (No. 81101553/ H1604). The author declares no competing financial interest.

\section{References}

1. Bianchi ME, Beltrame M, Paonessa G (1989) Specific recognition of cruciform DNA by nuclear protein HMG1. Science 243: 1056-1059.

2. Bustin M (1999) Regulation of DNA-dependent activities by the functional motifs of the high-mobility group chromosomal proteins. Mol Cell Biol 19: 5237-5246.

3. Wang $\mathrm{H}$, Bloom O, Zhang M, Vishnubhakat JM, Ombrellino M, et al. (1999) HMG-1 as a late mediator of endotoxin lethality in mice. Science 285: 248-251.

4. Andersson A, Covacu R, Sunnemark D, Danilov AI, Dal BA, et al. (2008) Pivota advance: HMGB1 expression in active lesions of human and experimental multiple sclerosis. J Leukoc Biol 84: 1248-1255.

5. Zhang S, Zhong J, Yang P, Gong F, Wang CY (2009) HMGB1, an innate alarmin, in the pathogenesis of type 1 diabetes. Int J Clin Exp Pathol 3: 24-38.

6. Han J, Zhong J, Wei W, Wang Y, Huang Y, et al. (2008) Extracellular high- mobility group box 1 acts as an innate immune mediator to enhance autoimmune progression and diabetes onset in NOD mice. Diabetes 57: 2118-2127.

7. Goodwin GH, Sanders C, Johns EW (1973) A new group of chromatinassociated proteins with a high content of acidic and basic amino acids. Eur J Biochem 38: 14-19.

8. Hill DA, Reeves R (1997) Competition between HMG-I(Y), HMG-1 and histone H1 on four-way junction DNA. Nucleic Acids Res 25: 3523-3531.

9. Hill DA, Pedulla ML, Reeves R (1999) Directional binding of HMG-I(Y) on fourway junction DNA and the molecular basis for competitive binding with HMG-1 and histone H1. Nucleic Acids Res 27: 2135-2144.

10. Locker D, Decoville M, Maurizot JC, Bianchi ME, Leng M (1995) Interaction between cisplatin-modified DNA and the HMG boxes of HMG 1: DNase footprinting and circular dichroism. J Mol Biol 246: 243-247.

11. Stros M, Reich J (1998) Formation of large nucleoprotein complexes upon binding of the high-mobility-group (HMG) box B-domain of HMG1 protein to supercoiled DNA. Eur J Biochem 251: 427-434.

12. Landsman D, Bustin M (1993) A signature for the HMG-1 box DNA-binding proteins. Bioessays 15: 539-546.

13. Ueda T, Chou H, Kawase T, Shirakawa H, Yoshida M (2004) Acidic C-tail of HMGB1 is required for its target binding to nucleosome linker DNA and transcription stimulation. Biochemistry 43: 9901-9908.

14. Wang H, Yang H, Czura CJ, Sama AE, Tracey KJ (2001) HMGB1 as a late mediator of lethal systemic inflammation. Am J Respir Crit Care Med 164: 1768-1773.

15. Weir HM, Kraulis PJ, Hill CS, Raine AR, Laue ED, et al. (1993) Structure of the HMG box motif in the B-domain of HMG1. EMBO J 12: 1311-1319.

16. Abdulahad DA, Westra J, Limburg PC, Kallenberg CG, Bijl M (2010) HMGB1 in systemic lupus Erythematosus: Its role in cutaneous lesions development Autoimmun Rev 9: 661-665.

17. Schierbeck $\mathrm{H}$, Lundback $\mathrm{P}$, Palmblad K, Klevenvall L, Erlandsson-Harris $\mathrm{H}$, et al. (2011) Monoclonal anti-HMGB1 (high mobility group box chromosomal protein 1) antibody protection in two experimental arthritis models. Mol Med 17: $1039-1044$

18. Andersson $\mathrm{U}$, Erlandsson-Harris $\mathrm{H}$ (2004) HMGB1 is a potent trigger of arthritis. J Intern Med 255: 344-350.

19. Rosenberg HF (2008) HMGB1, a novel biomarker of inflammatory demyelinating disease: an interview with Dr. Robert A. Harris. J Leukoc Biol 84: 1256-1258.

20. O'Brien BA, Fieldus WE, Field CJ, Finegood DT (2002) Clearance of apoptotic beta-cells is reduced in neonatal autoimmune diabetes-prone rats. Cell Death Differ 9: 457-464.

21. O'Brien BA, Geng X, Orteu CH, Huang Y, Ghoreishi M, et al. (2006) A deficiency in the in vivo clearance of apoptotic cells is a feature of the NOD mouse. $J$ Autoimmun 26: 104-115.

22. Oklota M, Mysliwiec J, Gorska M (2005) Contribution of apoptosis to pathogenesis of type 1 diabetes. Pol Arch Med Wewn 113: 179-184

23. Turley S, Poirot L, Hattori M, Benoist C, Mathis D (2003) Physiological beta cell death triggers priming of self-reactive $T$ cells by dendritic cells in a type-1 diabetes model. J Exp Med 198: 1527-1537.

24. O’Brien BA, Huang Y, Geng X, Dutz JP, Finegood DT (2002) Phagocytosis of apoptotic cells by macrophages from NOD mice is reduced. Diabetes 51 2481-2488.

25. Chen Y, Yan SS, Colgan J, Zhang HP, Luban J (2004) Blockade of late stages of autoimmune diabetes by inhibition of the receptor for advanced glycation end products. J Immunol 173: 1399-1405.

26. Bianchi ME (2007) DAMPs, PAMPs and alarmins: all we need to know about danger. J Leukoc Biol 81: 1-5. 